\title{
DETERMINASI VOLATILITAS KURS RUPIAH TERHADAP DOLAR AMERIKA
}

\author{
Ade Irma Nurhasanah1*, Soeharjoto2* \\ Program Studi Ekonomi Pembangunan, Fakultas Ekonomi dan Bisnis, Universitas Trisakti* \\ Jl. Kyai Tapa No. 1 Grogol, Jakarta 11440, Indonesia \\ E-mail: irma.adeish@gmail.com ${ }^{1}$ \\ E-mail:ryoto16@yahoo.com²
}

\begin{abstract}
Abstrak
Penelitian ini bertujuan untuk mengetahui determinasi volatilitas kurs Rupiah terhadap Dolar Amerika, dengan menggunakan data runtut waktu, berupa kuartalan, pada 2010-2017. Penelitian ini menggunakan metode regresi, yang menggunakan model Error Correction Model (ECM), dengan variabel dependen kurs Rupiah terhadap Dolar Amerika dan variabel independennya utang luar negeri, neraca transaksi berjalan, serta suku bunga Sertifikat Bank Indonesia (SBI). Adapun hasilnya menunjukkan bahwa dalam hubungan jangka pendek, utang luar negeri dan neraca transaksi berjalan tidak signifikan dengan kurs Rupiah terhadap Dolar Amerika, sedangkan suku bunga SBI berpengaruh positif dan signifikan dengan kurs Rupiah terhadap Dolar Amerika, Namun, untuk hubungan jangka panjang, seluruh variabel independen berpengaruh positif dan signifikan terhadap variabel dependen.
\end{abstract}

Kata Kunci: Kurs, Utang Luar Negeri, Neraca Transaksi Berjalan, Suku Bunga SBI

\begin{abstract}
Purpose of this study is to know about Rupiah exchange rate to US Dollar determination with quarterly time series data, from 2010-2017. Using Error Connection Model (ECM) with regression method, and dependent variable is Rupiah exchange rate to US Dollar, and independent variable is foreign debt, current account balance, and Sertifikat Bank Indonesia (SBI) interest rate. Result shown that at short term, foreign debt and current account were not significant, but SBI interest rate have a positive and significant effect from Rupiah to US Dollar. For long term, all of independent variable have positive and significant to dependent variable.
\end{abstract}

Key Word: Exchange Rate, Foreign Debt, Current Account Balance, SBI Interest Rate

\section{Pendahuluan}

Perdagangan internasional di era globalisasi berdampak pada semakin cepatnya perkembangan ekonomi dunia (Soeharjoto, 2016). Kesemuanya, tidak terlepas dari semakin banyak ditemukannya inovasi di berbagai bidang (Nakish, 2016). Apalagi pada saat ini, sudah ada ketentuan bahwa produk yang dihasilkan ramah lingkungan (Arafah, 2018). Namun, untuk memperlancar transaksi pembayarannya, digunakan hard currency, berupa Dolar Amerika Serikat (USD) (Sabtiadi, 2018). Dengan demikian, 
semakin meningkatnya perdagangan internasional, akan semakin dibutuhkannya Dolar Amerika, yang berdampak pada nilai tukar mata uangnya semakin kuat. Hal ini, sesuai dengan Krugman (2005), yang mengungkapkan bahwa nilai tukar merupakan variabel makro yang penting, terutama untuk menjaga kestabilan perekonomian suatu negara.

Mata uang memegang peran yang besar dalam menentukan kesejahteraan negara, terutama bagi negara yang sistem perokonomiannya terbuka. Padahal, kesejahteraan merupakan tujuan utama dari pembangunan ekonomi suatu negara (Soeharjoto, 2018). Untuk itu, dalam memenuhi kebutuhan masyarakatnya, perlu melakukan perdagangan internasional, yang menggunakan Dolar Amerika. Perdagangan internasional sendiri, sebenarnya juga ditujukan untuk mencapai economics of scale (Krugman, 1981). Perbandingan nilai mata uang dapat ditentukan dengan daya beli dari masing-masing negara (Cassel, 1922). Dengan demikian, diupayakan setiap negara dapat menjaga stabilitas nilai kursnya, dengan cara meningkatkan ekspor dan mengurangi impor serta pinjaman luar negeri, ataupun dengan meningkatkan penanaman modal asing (PMA).

Tren pertumbuhan kurs Rupiah mengalami penurunan dari 2010-2017. Rata-rata pertumbuhan kurs Rupah mengalami penurunan sebesar 6,06 persen terhadap Dolar Amerika. Kurs Rupiah mengalami peningkatan terbesar pada 2011 sebesar Rp8.843 dan penurunannya yang terparah pada 2015 menjadi sebesar Rp13.786. Keadaan ini, terlihat semenjak 2013 kurs Rupiah terus mengalami penurunan hingga nilai kursnya tembus di atas Rp10.000.

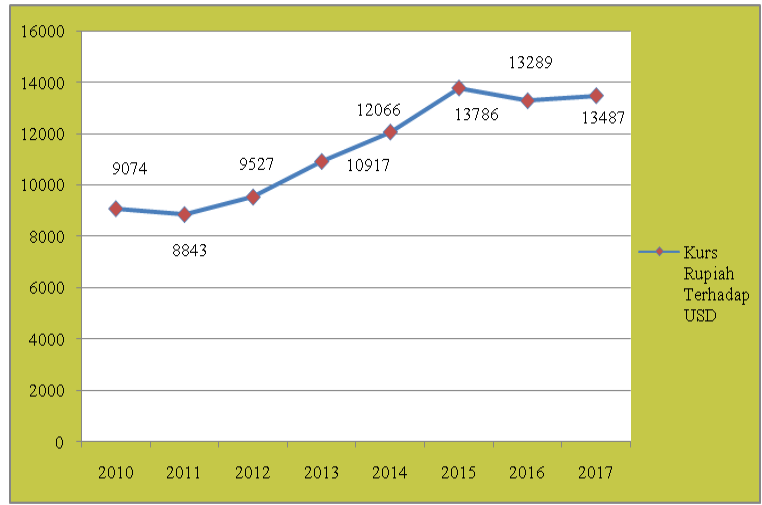

Gambar 1. Kurs Rupiah Terhadap Dolar Amerika, Pada 2010-2017 Sumber: Bank Indonesia

Neraca transaksi berjalan di Indonesia, pada 2010-2017 mengalami defisit setelah 2010, dengan rata-rata pertumbuhannya minus 104,679 persen. Kondisi ini terjadi karena rata-ratanya yang positif hanya pada barang sebesar 16.812,93 juta Dolar Amerika, sedangkan yang lainnya negatif, yakni jasa-jasa sebesar minus 8.769,2 juta Dolar Amerika, pendapatan primer sebesar minus 27.597,9 juta Dolar Amerika, dan pendapatan sekunder sebesar 12.598,8 juta Dolar Amerika.

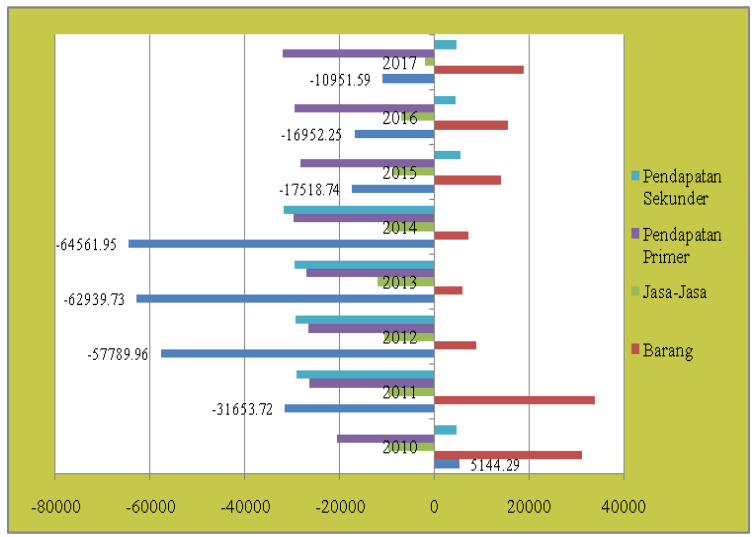

Gambar 2. Neraca Transaksi Berjalan di Indonesia, Pada 2010-2017 (Juta Dolar Amerika)

Sumber: Bank Indonesia

Utang luar negeri di Indonesia mempunyai tren yang meningkat pada 2010-2017, dengan rata-rata pertumbuhan 8,29 persen, yakni sebesar 277.849,1 juta Dolar Amerika. Rata-rata pertumbuhan utang pemerintahnya sebesar 6,33 persen dan utang dalam 
negerinya sebesar 11,22 persen. Pertumbuhan utang luar negeri pemerintah yang tertinggi pada 2017 sebesar 14,11 persen dan terendahnya pada 2013 sebesar minus 2,04 persen. Untuk utang luar negeri swasta yang terbesar pada 2011 sebesar 27,38 persen dan terendahnya sebesar minus 3,81 persen pada 2013.

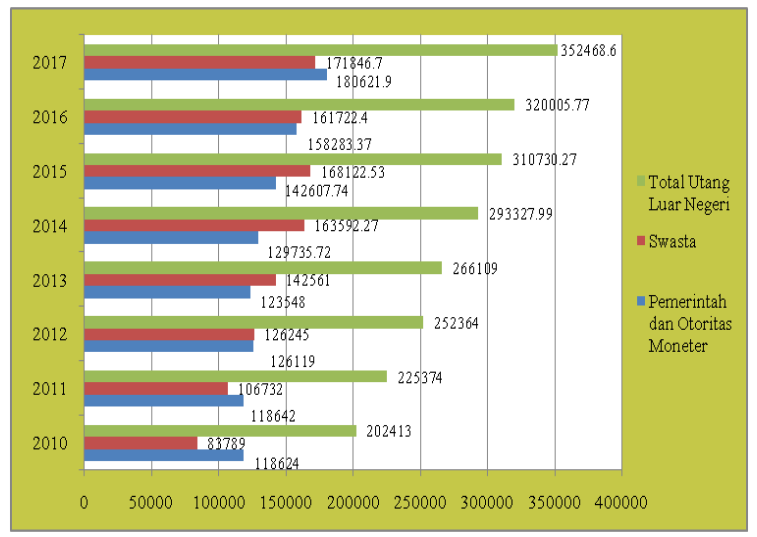

Gambar 3. Total Utang Luar Negeri Indonesia, Pada 2010-2017 (Juta Dolar Amerika) Sumber: Bank Indonesia

Tingkat suku bunga SBI mengalami tren yang fluktuatif pada 2010-2017. Rata-rata pertumbuhan suku bunga sebesar minus 3,31 persen, yang pada 2013 terjadi peningkatan suku bunga SBI tertinggi, yakni sebesar 15,304 persen dan terendahnya pada 2016 sebesar minus 23,33 peren. Fluktuatif dari suku bunga SBI akan berdampak pada sektor lain, sehingga Pemerintah perlu merespon dengan cepat, agar kondisi ekonomi tetap stabil.

Penelitian mengenai kurs sudah banyak dilakukan dan terungkap bahwa utang luar negeri, neraca transaksi berjalan dan suku bunga SBI mempunyai pengaruh yang positif dan signifikan dengan kurs Rupiah terhadap Dolar Amerika. Adapun beberapa hasil penelitiannya yang dilakukan Yudiarti (2018), mengungkapkan bahwa utang luar negeri dan neraca transaksi berjalan berpengaruh positif dan signifikan terhadap nilai tukar, tetapi suku bunga BI tidak signifikan terhadap nilai tukar. Mokodongan (2018), memperoleh hasil bahwa suku bunga SBI berpengaruh positif dan signifikan terhadap kurs Rupiah, sedangkan neraca transaksi berjalan mempunyai pengaruh yang negatif dan signifikan terhadap kurs Rupiah. Yulianti (2014) mengungkapkan bahwa dalam jangka pendek dan panjang tingkat suku bunga SBI mempunyai pengaruh dan signifikan dengan nilai tukar Rupiah terhadap Dolar Amerika. Puspitaningrum (2014), menemukan bahwa suku bunga SBI berpengaruh terhadap nilai tukar Rupiah.

Kurs Rupiah yang stabil terhadap Dolar Amerika diperlukan untuk menjaga kondisi ekonomi Indonesia, agar perekonomiannya tetap kondusif. Untuk itu, perlu dilakukan penelitian determinasi volatilitas kurs Rupiah terhadap Dolar Amerika, sehingga dengan mengetahui faktor yang mempengaruhi perubahan nilai kurs Rupiah terhadap Dolar Amerika, dapat digunakan untuk membantu menjaga kestabilan kurs Rupiah, dengan membuat kebijakan yang terkait dengan faktor tersebut.

\section{Metode Penelitian}

Penelitian faktor yang mempengaruhi kurs Rupiah terhadap Dolar Amerika, menggunakan regresi dengan model Error Correction Model (ECM), yang bertujuan untuk mengetahui hubungan jangka pendek dan jangka panjang dari determinasi kurs Rupiah terhadap Dolar Amerika. Data menggunakan data sekunder dalam runtut waktu dengan sampel sebanyak 32, berupa kuartalan, pada 2010-2017, yang berasal dari Bank Indonesia dan Badan Pusat Statistik. Variabel menggunakan kurs Rupiah terhadap Dolar Amerika sebagai variabel dependen dan utang luar negeri, neraca transaksi berjalan, serta suku bunga SBI sebagai variabel independen. Kurs merupakan harga satu satuan mata uang dalam satuan mata uang lain. Utang luar negeri merupakan penerimaan negara dalam bentuk devisa yang dapat dirupiahkan maupun dalam bentuk barang dan atau jasa yang diterima dari Pemberi Pinjaman atau Hibah Luar Negeri (PPHLN), yang mengakibatkan pembayaran di masa yang akan datang. Neraca transaksi berjalan merupakan segala transaksi yang berasal dari perdagangan barang dan 
jasa serta pendapatan yang berasal dari investasi asing. Suku Bunga SBI merupakan surat berharga yang diterbitkan oleh Bank Indonesia sebagai pengakuan utang berjangka waktu pendek dengan system diskonto atau bunga. Adapun model dalam penelitian ini adalah:

$$
\mathrm{KURS}_{\mathrm{t}}=\beta_{0}+\beta_{1} \mathrm{ULN}_{\mathrm{t}}+\beta_{2} \mathrm{CA}_{\mathrm{t}}+\beta_{3} \mathrm{SB}_{\mathrm{t}}+\varepsilon_{\mathrm{t}}
$$

\section{Keterangan:}

KURS : Kurs Rupiah terhadap Dolar Amerika (Rupiah).

ULN : Utang luar negeri (Juta Dolar Amerika).

CA : Neraca Transaksi Berjalan (Juta Dolar Amerika).

SB

: Suku Bunga SBI (Persen).

\section{Analisis dan Pembahasan}

Perkembangan indikator ekonomi makro di Indonesia, Pada 2010-2017 mengalami fluktuatif dengan beragam tren. Kurs Rupiah terhadap Dolar Amerika memiliki tren yang menurun, yang pada 2010.Q1 sebesar 9.161 menjadi sebesar 13.616 pada 2017.Q4. Utang luar negeri memiliki tren yang meningkat, yang pada 2010.Q1 sebesar 180.834 juta Dolar Amerika menjadi 352.899 juta Dolar Amerika pada 2017.Q4. Neraca transaksi berjalan mengalami fluktuatif dengan nilai negatif dengan trend yang mengalami peningkatan, yang pada 2010.Q1 sebesar 1890,52 juta Dolar Amerika menjadi sebesar minus 5.890,65 juta Dolar Amerika pada 2017.Q4. Suku bunga SBI mengalami fluktuatif yang mengarah pada tren penurunan, yakni sebesar 6,50 persen pada 2010.Q1 menjadi sebesar 4,75 persen pada 2017.Q4.

TABEL I

Nilai Kurs, Utang LUAR NegERI, NERACA TranSAKSI BERJALAN, DAN SUKU BUNGA SBI KUARTALAN DI INDONESIA,

\begin{tabular}{c|c|c|c|c}
\multicolumn{6}{c}{ PADA 2010-2017 } \\
\hline & KURS & ULN & CA & SB \\
& (Rp) & & & (Persen) \\
& & (USD & (USD & \\
\hline
\end{tabular}

\begin{tabular}{c|c|c|c|c}
\hline & & Juta) & Juta) & \\
\hline Average & 11374 & 271245 & -3937 & 6,38 \\
\hline Maximum & 14730 & 352899 & 2947 & 7,75 \\
\hline Minumum & 8640 & 180834 & -10126 & 4,75 \\
\hline $\begin{array}{c}\text { Standar } \\
\text { Deviasi }\end{array}$ & 2016,14 & 50139,78 & 3424,38 & 0,9959 \\
\hline
\end{tabular}

Pengujian akar-akar unit untuk semua variabel yang digunakan dalam analisis runtun waktu, perlu dilakukan pengujian bahwa data yang digunakan harus bersifat stasioner, yang dalam penelitian ini menggugunakan uji Augmented Dickey-Fuller (ADF). Adapun hasilnya, kesemua variabel yang terdapat dalam model belum stasioner pada tingkat level dapat dilihat pada tabel 2 .

Uji derajat integrasi dilakukan apabila variabel-variabel tidak stasioner pada uji akar-akar unit ditingkat level. Untuk tahap selanjutnya, dilakukan pengulangan pengujian dengan menggunakan uji ADF (Augmented Dickey-Fuller) pada tingkat first difference, dengan hasil seluruh variabel yang diestimasi dapat dilanjutkan dengan melakukan pengujian kointegrasi dapat dilihat pada tabel 3.

TABEL II

UJI AKAR-AKAR UNIT PADA LEVEL

\begin{tabular}{c|c|c|c|c}
\hline Variabel & $\begin{array}{c}\text { Nilai ADF } \\
\text { Test }\end{array}$ & $\begin{array}{c}\text { Nilai Kritis } \\
\text { Mackinnon } \\
5 \%\end{array}$ & Probabilitas & Keputusan \\
\hline KURS & -0.667232 & -2.960411 & 0.8406 & $\begin{array}{c}\text { Tidak } \\
\text { Stasioner }\end{array}$ \\
\hline ULN & -0.886541 & -2.960411 & 0.7790 & $\begin{array}{c}\text { Tidak } \\
\text { Stasioner }\end{array}$ \\
\hline CA & -2.293020 & -2.960411 & 0.1804 & $\begin{array}{c}\text { Tidak } \\
\text { Stasioner }\end{array}$ \\
\hline SB & -1.235456 & -2.963972 & 0.6456 & $\begin{array}{c}\text { Tidak } \\
\text { Stasioner }\end{array}$ \\
\hline
\end{tabular}

TABEL III

UJi DERAJAT INTEGRASI PADA DERAJAT INTEGRSI PERTAMA

\begin{tabular}{c|c|c|c|c}
\hline Variabel & $\begin{array}{c}\text { Nilai ADF } \\
\text { Test }\end{array}$ & $\begin{array}{c}\text { Nilai Kritis } \\
\text { Mackinnon 5\% }\end{array}$ & Probabilitas & Keputusan \\
\hline KURS & -5.293363 & -2.963972 & 0.0002 & Stasioner \\
\hline
\end{tabular}




\begin{tabular}{c|c|c|c|c} 
ULN & -5.654001 & -2.963972 & 0.0001 & Stasioner \\
\hline CA & -7.042822 & -2.963972 & 0 & Stasioner \\
\hline SB & -3.895072 & -2.963972 & 0.0058 & Stasioner \\
\hline
\end{tabular}

Setelah dilakukan uji stasioneritas pada seluruh variabel dengan hasil stasioner dan memiliki derajat yang sama, maka dapat dilanjutkan dengan uji kointegrasi guna melihat hubungan jangka panjang dari model tersebut dengan menggunakan Engle-Granger (EG). Adapun hasil uji kointegrsi menunjukkan bahwa variabel KURS dengan variabel independen ULN, CA, dan SB memiliki kointegrasi. Didapatkan bahwa residual stasioner pada tingkat level yang terlihat dari nilai absolut ADF lebih besar dari nilai kritisnya yaitu -3.768884 > -2.960411 (Prob. 0.0150). Artinya, variabel-variabel yang diteliti telah berkointegrasi pada derajat yang sama. Hal ini menujukkan terjadinya keseimbangan jangka panjang antar seluruh variabel kurs Rupiah, utang luar negeri, neraca transaksi berjalan, dan suku bunga SBI. Pengujian ini dapat dilanjutkan ke uji ECM (Error Correction Model).

TABEL IV

Nilai Uji Kointegrasi Metode ADF PADA TingKat LeVEL

\begin{tabular}{c|c|c|c|c}
\hline Variabel & $\begin{array}{c}\text { Nilai ADF } \\
\text { Test }\end{array}$ & $\begin{array}{c}\text { Nilai Kritis } \\
\text { Mackinnon 5\% }\end{array}$ & Probabilitas & Keputusan \\
\hline ECT(-1) & -3.491894 & -2.960411 & 0.015 & Stasioner \\
\hline
\end{tabular}

Dari hasil estimasi jangka pendek, diperoleh hasil sebagai berikut:

TABEL V

HASIL ESTIMASI PERSAMAAN JANGKA PENDEK

\begin{tabular}{c|c|c|c|c}
\hline Variabel & Koefisien & Std. Error & t-Statistik & Probabilitas \\
\hline $\mathrm{C}$ & 428.2169 & 114.4209 & 3.742471 & 0.0009 \\
\hline $\mathrm{D}(\mathrm{ULN})$ & -0.043926 & 0.017261 & -2.544789 & 0.0172 \\
\hline $\mathrm{D}(\mathrm{CA})$ & 0.001854 & 0.0356 & 0.052079 & 0.9589 \\
\hline $\mathrm{D}(\mathrm{SB})$ & 670.2032 & 164.7152 & 4.6886 & 0.0004 \\
\hline ECT(-1) & -0.310717 & 0.128446 & -2.419055 & 0.0229 \\
\hline $\begin{array}{c}\text { Adj } \\
\text { R-Squared }\end{array}$ & 0.463418 & & & \\
\hline
\end{tabular}

\begin{tabular}{l|l} 
Prob. F-stat & 0.000378 \\
\hline
\end{tabular}

Berdasarkan hasil penelitian untuk uji global (Uji F), diperoleh nilai probabilitas F-statistik sebesar 0.000378. Dengan demikian, karena nilainya $0.000378<0.05$, berarti dalam jangka pendek, minimal terdapat satu variabel independen yang mempunyai pengaruh signifikan terhadap variabel dependen.

Untuk uji individunya (uji t), diperoleh hasil sebagai berikut:

1. Utang luar negeri mempunyai nilai probabilitas 0,0172. Dengan demikian, walaupun $0,0172<0,05$ tetapi karena memiliki tanda negatif, berarti variabel utang luar negeri tidak signifikan dengan kurs Rupiah terhadap Dolar Amerika.

2. Neraca transaksi berjalan mempunyai nilai probabilitas 0,9589. Dengan demikian, karena 0,9589>0,05 berarti variabel neraca transaksi berjalan tidak signifikan dengan kurs Rupiah terhadap Dolar Amerika.

3. Suku bunga SBI mempunyai nilai probabilitas 0,0004. Dengan demikian karena 0,0004<0,05 dan tandanya positif, berarti suku bunga SBI berpengaruh positif dan signifikan dengan kurs Rupiah terhadap Dolar Amerika.

4. ECT(-1) mempunyai nilai probabilitas sebesar 0.0229. Dengan demikian karena $0,0229<0,05$ dengan tanda yang negatif, sehingga model penelitian ini telah memenuhi syarat model ECM.

Untuk koefisien determinasi diperoleh nilai Adjusted R-squared adalah sebesar 0.4634. Adapun artinya dalam jangka pendek, utang luar negeri, neraca transaksi berjalan dan suku bunga SBI mampu menjelaskan variasi kurs Rupiah terhadap Dolar Amerika sebesar 46.34 persen, sedangkan sisanya yang 53.66 persen dijelaskan oleh variabel lain, namun tidak dimasukkan ke dalam model. 
Dari hasil estimasi jangka panjang, diperoleh hasil sebagai berikut:

TABEL VI.

\begin{tabular}{c|c|c|c}
\multicolumn{4}{c}{ HASIL ESTIMASI PERSAMAAN JANGKA PANJANG } \\
\hline $\begin{array}{c}\text { Variabel } \\
\text { Bebas }\end{array}$ & Koefisien & t Statistik & Probabilitas \\
\hline C & -3094.18 & -2.77649 & 0.0097 \\
\hline ULN & 0.042672 & 16.05219 & 0 \\
\hline CA & 0.089775 & 2.371617 & 0.0248 \\
\hline SB & 509.2636 & 4.440021 & 0.0001 \\
\hline $\begin{array}{c}\text { Adj } \\
\text { R-Squared }\end{array}$ & 0.909137 & & \\
\hline Prob. F Stat & 0 & &
\end{tabular}

Berdasarkan tabel 6 hasil penelitian untuk uji global (Uji F), diperoleh nilai probabilitas F-statistik sebesar 0,000000. Dengan demikian, karena nilainya $0.000000<0.05$, berarti dalam jangka pendek, minimal terdapat satu variabel independen yang mempunyai pengaruh signifikan terhadap variabel dependen.

Untuk uji individunya (uji t), diperoleh hasil sebagai berikut:

1. Utang luar negeri mempunyai nilai probabilitas 0,0000. Dengan demikian, karena $0,000<0,05$ dan tandanya positif, berarti utang luar negeri berpengaruh positif dan signifikan dengan kurs Rupiah terhadap Dolar Amerika.

2. Neraca transaksi berjalan mempunyai nilai probabilitas 0,0248. Dengan demikian, karena $0,0248<0,05$ dan tandanya positif, berarti variabel neraca transaksi berjalan berpengaruh positif dan signifikan dengan kurs Rupiah terhadap Dolar Amerika.

3. Suku bunga SBI mempunyai nilai probabilitas 0,0001. Dengan demikian karena $0,0001<0,05$ dan tandanya positif, berarti suku bunga SBI berpengaruh positif dan signifikan dengan kurs Rupiah terhadap Dolar Amerika.

Koefisien determinasi diperoleh nilai Adjusted R-squared adalah sebesar 0.9091. Adapun artinya dalam jangka panjang, utang luar negeri, neraca transaksi berjalan dan suku bunga SBI mampu menjelaskan variasi kurs Rupiah terhadap Dolar Amerika sebesar 90,91 persen, sedangkan sisanya yang 9.09 persen dijelaskan oleh variabel lain, namun tidak dimasukkan ke dalam model.

Utang luar negeri merupakan salah satu komponen yang mempengaruhi fluktuasi kurs Rupiah. Dalam hubungan jangka pendek, walaupun utang luar negeri signifikan tetapi arahnya berlawanan dengan teori. Adapun artinya ketika utang luar negeri naik sebesar 1 juta Dolar Amerika maka kurs Rupiah terhadap Dolar Amerika akan turun atau terapresiasi sebesar 1 Rupiah, ceteris paribus. Hal ini disebabkan, pada saat penerimaan utang luar negeri maka cadangan mata uang asing yaitu Dolar Amerika bertambah dan membuat kurs Rupiah terapresiasi dalam jangka pendek, Namun, untuk hubungan jangka panjang, utang luar negeri berpengaruh secara positif dan signifikan dengan kurs Rupiah terhadap Dolar Amerika. Artinya ketika utang luar negeri naik sebesar 1 juta Dolar Amerika maka akan meningkatkan kurs Rupiah terhadap Dolar Amerika atau depresiasi sebesar 1 Rupiah, ceteris paribus. Hasil ini, dapat terjadi karena dalam jangka panjang kebutuhan mata uang asing (Dolar Amerika) akan meningkat, yang disebabkan oleh jatuh tempo masa pembayaran utang luar negerinya, yang berdampak pada perlemahan kurs Rupiah (terdepresiasi).

Dalam hubungan jangka pendek, neraca transaksi berjalan tidak berpengaruh secara signifikan terhadap kurs Rupiah terhadap Dolar Amerika. Kondisi ini terjadi karena transaksi yang menggunakan Dolar Amerika pada umumnya hanya dilakukan para pengusaha untuk memenuhi kebutuhan produksi (bahan baku impor), sehingga tidak berpengaruh dalam jangka pendek. Namun, untuk hubungan jangka panjang, neraca transaksi berjalan berpengaruh secara positif dan signifikan dengan kurs Rupiah terhadap Dolar Amerika. Adapun artinya bahwa ketika neraca transaksi berjalan naik sebesar 1 juta Dolar Amerika maka akan meningkatkan kurs Rupiah terhadap Dolar Amerika (depresiasi) sebesar 1 
Rupiah, ceteris paribus. Kondisi ini, sesuai dengan Marshall (1923) dan Lerner (1944), yang mengungkapkan bahwa apabila penerimaan dari perdagangan barang dan jasa serta transfer lebih besar dari pembayarannya, akan terjadi surplus, dan begitu pula sebaliknya.

Suku bunga SBI berpengaruh positif dan signifikan dengan kurs Rupiah terhadap Dolar Amerika, baik dalam hubungan jangka pendek maupun jangka panjang. Adapun artinya ketika suku bunga naik sebesar 1 persen maka akan meningkatkan kurs Rupiah terhadap Dolar Amerika (depresiasi) sebesar 1 Rupiah, ceteris paribus. Kondisi ini, sesuai dengan yang diungkapkan Fisher (1930), yang terkait dengan teori International Fisher Effect (IFE), yakni bahwa tingkat suku bunga yang berbeda antara dua negara disebabkan karena adanya perbedaan perkiraan terhadap tingkat inflasi suatu negara. Namun, tingkat suku bunga yang tinggi tidak memberikan jaminan terhadap penguatan nilai tukar mata uang suatu negara. Adapun maknanya dari implikasi teori ini adalah orang tidak bisa menikmati keuntungan lebih tinggi hanya dengan menanamkan dana ke negara yang mempunyai suku bunga nominal tinggi, karena nilai mata uang negara yang suku bunganya tinggi akan terdepresiasi sebesar selisih bunga nominal dengan negara yang memiliki suku bunga nominal lebih rendah. Artinya, tingkat suku bunga yang tinggi akan membuat mata uang tersebut cenderung menurun (terdepresiasi), sementara mata uang dengan tingkat bunga yang rendah akan cenderung meningkat (apresiasi).

\section{Simpulan dan Hasil}

Penelitian determinasi volatilitas kurs Rupiah terhadap Dolar Amerika, dengan regresi model ECM, dapat diperoleh hubungan untuk jangka pendek dan panjang. Adapun hasilnya adalah koefisien determinasi (adj- $\mathrm{R}^{2}$ ) untuk jangka pendek sebesar 0,46 dan jangka panjangnya sebesar 0,91. Untuk hubungan jangka pendek utang luar negeri dan neraca transaksi berjalan tidak signifikan, tetapi jangka panjangnya mempunyai pengaruh yang positif dan signifikan dengan kurs Rupiah terhadap Dolar Amerika. Suku bunga SBI berpengaruh positif dan signifikan dengan kurs Rupiah terhadap Dolar Amerika dalam jangka pendek dan panjang. Untuk menjaga kestabilan kurs, dapat dilakukan dengan mengurangi utang luar negeri dengan meningkatkan PMA yang diprioritaskan untuk menunjang peningkatan komoditas ekspor yang memiliki multiplier efek terhadap kesejahteraan masyarakat, serta meningkatkan penggunaan produk dalam negeri, kualitas dan kuantitas SDM, pariwisata, serta bank sentral beserta masyarakat tetap menjaga kestabilan kurs Rupiah.

\section{DAFTAR PUSTAKA}

A. Arafah, Willy, Lucky Nugroho, Rowlan Takaya, Soeharjoto Soekapdjo. 2018. Marketing Strategy for Renewable Energy Development In Indonesia Context Today. International Journal of Energy Economics and Policy. Vol. 8(5). 181-186.

B. Cassel, Gustav. (1922), Money and Foreign Exchange after 1914, New York: The Macmillan Company.

C. Fisher, I. 1930. The Theory of Interest. Mcmillan: New York

D. Krugman, Paul R. and Maurice Obstfeld. (2005). International Economics: Theory and Practice. $7^{\text {th }}$ ed. Addison-Wesley. Boston.

E. Krugman, P. (1981). Intraindustry Specialization and the Gains from Trade. Journal of Political Economy. Vol. 89(5). 959-973.

F. Lerner, A. 1944. The Economics of Control. New York: Mcmillan.

G. Mokodongan, Zefanya Z.M, Tri Oldy Rotinsulu, Dennij Mandeij. 2018. Analisis Fluktuasi Tingkat Kurs Rupiah (IDR) Terhadap Dollar Amerika (USD) Pada Sistem Kurs Mengambang Bebas di Indonesia Dalam Periode 
2007.1-2014.4. Jurnal Berkala Ilmiah. Vol. 18(2). 135-145.

H. Marshall, A. 1923. Money, Credit and Commerce. London: Mcmillan and Co.

I. Nakish, Moh. 2016. Belajar dari Amerika Dalam Mempromosikan Pertumbuhan Ekonomi (Economic Growth) Melalui Inovasi (Innovation) dan Persaingan (Competition). Jurnal Akuntansi, Ekonomi dan Manajemen Bisnis. Vol. 4(2). 158-141.

J. Puspitaningrum, Roshita. Suhadak, Zahroh Z. A. 2014. Pengaruh Tingkat Inflasi, Tingkat Suku Bunga SBI, dan Pertumbuhan Ekonomi Terhadap Nilai Tukar Rupiah (Studi Pada Bank Indonesia Periode Tahun 2003-2012). Jurnal Administrasi Bisnis. Vol. 8(1). 1-9.

K. Sabtiadi, Kurniawan dan Dwi Kartikasari. 2018. Analisis Pengaruh Ekspor Impor Terhadap Nilai Tukar USD dan SGD. Jurnal Akuntansi, Ekonomi dan Manajemen Bisnis. Vol. 6(2). 135-141.

L. Soeharjoto. 2018. Peta Kemampuan Keuangan Daerah Kabupaten dan Kota di Provinsi Jawa Tengah. Jurnal Akuntansi, Ekonomi dan Manajemen Bisnis. Vol 6(2). 240-248.

M. Soeharjoto. 2016. Pengaruh Penanaman Modal Asing dan Tingkat Daya Saing Terhadap Ekspor Industri Manufaktur Indonesia. Media Ekonomi. Vol. 24(2). 161-174.

N. Yudiarti, Tri. Emilia, Candra Mustika. 2018. Pengaruh Utang Luar Negeri, Tingkat Suku Bunga dan Neraca Transaksi Berjalan Terhadap Nilai Tukar Rupiah Terhadap Dolar Amerika Serikat. Jurnal Perdagangan, Industri dan MOneter. Vol. 6(1). Januari.14-22.

O. Yulianti, Iin Nurul. 2014. Pengaruh Jumlah Uang Beredar (M2), Tingkat Suku Bunga SBI, Impor, dan Cadangan Devisa Terhadap Nilai
Tukar Rupiah Per Dolar Amerika Tahun 2001-2013. Economics Development Analysis Journal. Vol. 3(2). 284- 292.

P. www.bi.go.id

Q. www.bps.go.id 